\title{
May life history traits be used as indices of population viability?
}

\author{
M. -J. Rochet *
}

Laboratoire MAERHA, IFREMER, Rue de I'lle d'Yeu, B.P. 21105, 44311 Nantes Cedex 03, France

* : tel: 33.2.40.37.41.21, fax: 33.2.40.37.40.75, e-mail: mjrochet@ifremer.fr

\begin{abstract}
:
Concern has been raised that the widely used spawning stock biomass might not be a sensitive index of the reproductive potential of fish populations. On the other hand, there is increasing evidence that fishing affects life history traits of fish. Fish compensate for fishing mortality by faster growth, earlier maturity and increased fecundity. Because life history traits are affected by fishing and are also critical in determining the population growth rate, they may be used as indices of population viability. In this paper, the traits that meet both criteria are investigated among age-at-maturity, fecundity and growth. In the framework of matrix population models, the life table response experiments (LTRE) method is used to quantify the effects of fishing on demographic parameters, and the contributions of these effects to the population growth rate. This approach is used for comparing parameters and population growth rates of flatfish populations between periods with different fishing pressure. It is found that ageat-maturity, the proportion of repeat spawners in the spawning stock and some proxy for lifetime fecundity may be used as indices of population viability.
\end{abstract}

Keywords: population viability indices; sensitivity analysis; population growth rate; fishing effects 


\section{Introduction}

Currently used indices of population condition or viability mainly involve fishing mortality rates, recruitment indices, and biomasses of the stock and of the spawning stock (SSB). Only SSB can be regarded as an index of population viability, but it suffers several disadvantages. It is estimated from complex models and relies on estimates of the numerous parameters of these models. Environmental fluctuations, sampling variance and measurement errors result in uncertainties in these estimates; even if they are measurable, these uncertainties propagate in the complex models in a way which is difficult to quantify. Added to model mis-specification, this can result in high uncertainty in spawning stock biomass estimates (Walters and Ludwig, 1981; Beamish and McFarlane, 1989; Smith et al., 1993). Measuring and taking into account uncertainties has become an important part of fisheries stock assessment. Moreover, SSB has to be compared to biological reference points which are themselves subject to high uncertainties. In addition, concern has been raised that spawning stock biomass is not a sensitive index of the reproductive potential of exploited populations (Marshall et al., 1998; Marteinsdottir and Thorarinsson, 1998; Rochet, Submitted), partly due to maternal effects on egg production and quality. Younger spawners spawn less and smaller eggs with lower survival (Mann and Mills, 1979; Buckley et al., 1991; Solemdal, 1997; Trippel et al., 1997; Trippel, 1998) during a shorter season, reducing the probability that larvae will find good development conditions (Hutchings and Myers, 1993; Trippel et al., 1997). Indices incorporating effects of spawner age or size on fecundity (Leaman, 1986; Lambert, 1990; Katsukawa, 1997; Marshall et al., 1998; Marteinsdottir and Thorarinsson, 1998), and on egg size and egg and larval viability (MacKenzie et al., 1998; Murawski et al., 1998) should improve stock assessments and the reliability of population projections. A good index of population viability is Lotka's intrinsic population growth rate $r$, as suggested by Hutchings and Myers (1994), because it incorporates all vital rates involved in population growth.

However, monitoring $r$ requires annual estimates of age-specific fecundity and survival rates, including early survival. This would need additional sampling of biological parameters, some of which are highly variable and difficult to measure (Hoenig et al., 1990). A high precision in the estimates of early vital rates is necessary because small variations in them lead to large changes in population dynamics (Beyer, 1989; Koslow, 1992). In fact, a sufficient precision may be afforded only at high costs in terms of sampling and data handling (Smith, 1985). It may be an unachievable task to monitor such a complex system as a fish population with only one integrated index. Monitoring several sensitive, model-free and field-measured indices might give a more comprehensive and less uncertain information. Good sustainability indices in the fisheries context should at least i) be affected by fishing ii) be determining for the population dynamics and viability iii) be comparable to reference points iv) have a potential to reverse if fishing pressure is released.

In this study the demographic traits that meet at best the first two criteria are investigated among age at maturity, fecundity, and growth by sensitivity analysis in the framework of matrix population 
models. The proportion of spawners in the stock and the proportion of repeat spawners in the spawning stock are also considered as indices of the reproductive potential of the population. The life table response experiments (LTRE) method combines sensitivity analysis of the population growth rate to each parameter with information on the actual variation in the parameters in a retrospective analysis, to determine which parameters are responsible for the observed change in the population growth rate (Caswell, 1989a; Caswell, 1996). The basic idea is that exploitation results in a significant reduction in adult and sometimes in juvenile survival. These changes will reduce the growth rate of the population, which should become extinct. Only if other life-history parameters vary in such a way as to counterbalance the reduction of adult survival can the population persist. Indeed, there is increasing knowledge that fishing affects life history traits in flatfish and other teleosts. Fish compensate for fishing mortality by faster growth, earlier maturity and increased fecundity (Ware, 1985; Horwood et al., 1986 ; Rijnsdorp, 1994; Trippel, 1995; Rochet, 1998). LTRE allow to compare the relative contributions of beneficial changes in reproduction in the balance against deleterious effects of fishing on the survival of juvenile and adult fish.

This approach is used for comparing demographic parameters and population growth rates of populations between periods characterized by different fishing pressures. Flatfish populations with different life history strategies that have been monitored for many years have been selected: North sea plaice, Greenland halibut off Labrador, and Dover sole off California.

\section{Material and methods}

\subsection{A population model}

The population dynamics of fish is described by a stage-structured matrix population model (Caswell, 1989b). Whereas it is a class of linear models, I do not claim that fish population dynamics is independent of population density and time invariant. The basic assumption of this study is that populations develop compensatory responses to fishing. The linear model is used to compare sets of parameters in different conditions, by projecting how differently the population would behave if these conditions were to be maintained.

The life cycle of a fish is described by a life cycle graph (Caswell, 1982; Caswell, 1989b) where the first stage is recruits, the second stage is first-time spawners, and all subsequent stages are older ageclasses. The time-step between the repeat spawners is one year, whereas the time-step from any of them to recruits is the age at recruitment, and the time-step from recruits to first-time spawners is age at maturity minus age at recruitment (Fig. 1). Reproduction is assumed to occur during a short breeding season (birth-pulse population) once a year. However, not all animals mature at the same age. In the model this is described by assuming that a proportion (1- $\left.\alpha^{\prime \prime}\right)$ of recruits mature at age $\alpha^{\prime}$, and the remaining at $\alpha^{\prime}+1$. This amounts to a steep maturity ogive. 


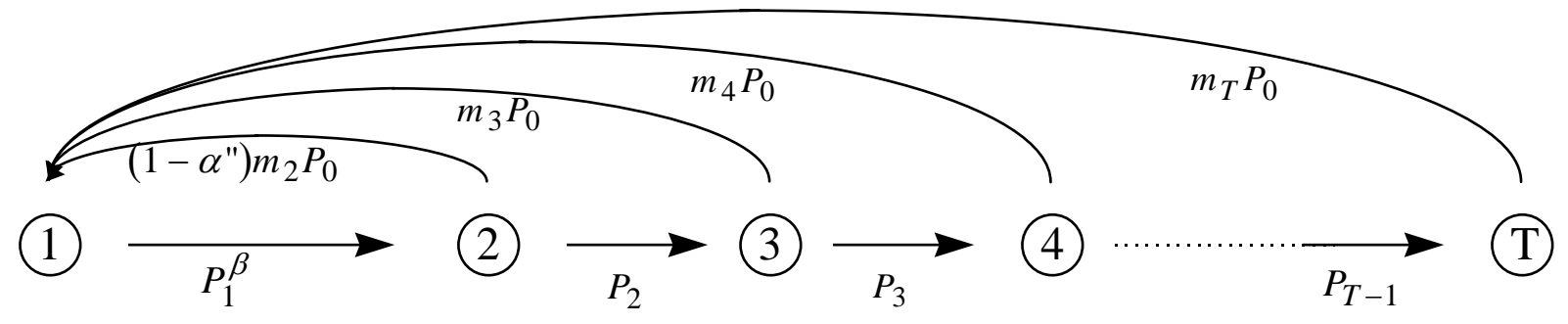

Figure 1: Life cycle graph for fish populations. The age at maturity in the population is $\alpha=\alpha^{\prime}+\alpha^{\prime \prime}=$ floor $(\alpha)+\alpha^{\prime \prime}$. The nodes are the stages: 1: recruits (age $\left.r\right) ; 2$ : first-time spawners (age $\left.\alpha^{\prime}\right)$; 3...T: repeat spawners (ages $\left.\alpha^{\prime}+1 \ldots \alpha^{\prime}+\mathrm{T}-2\right) . \beta=\alpha^{\prime}-r$. The coefficient on the arc from node $j$ to node $i$ gives the numbers of individuals of stage $i$ contributed per individual of stage $j: P_{i}$ : probability of surviving to next year when in stage $i$ (except $P_{0}$ : probability of surviving from egg to recruitment); $m_{i}$ : fecundity of stage $i$.

This life cycle graph is associated with an age-structured projection matrix and can be used to derive its characteristic equation (Caswell, 1982; Caswell, 1989b). Assuming that fish fecundity is determined by length $\left(m=a L^{b}\right)$ and that survival of stages $2 \ldots T$ is the exponential of total instantaneous mortality rates, $Z_{i}$, like in fisheries models $\left(P_{i}=e^{-Z_{i}}\right)$, the characteristic equation associated with the graph in Figure 1 is:

$$
\lambda^{\alpha^{\prime}}-\left(1-\alpha^{\prime \prime}\right) a L_{2}^{b} P_{0} P_{1}^{\beta}-P_{0} P_{1}^{\beta} \sum_{i=3}^{T} a L_{i}^{b} \lambda^{2-i}\left(\prod_{j=2}^{i-1} e^{-Z_{j}}\right)=0
$$

The real root of this equation is also the dominant eigenvalue of the associated matrix and the population growth rate $\lambda$ related to Lotka's intrinsic population growth rate $r$ by $\lambda=e^{r}$. If $\lambda=1$, the population is asymptotically stable, it declines if $\lambda<1$ and grows exponentially otherwise. The asymptotically stable population structure $w$ (the associated right eigenvector of the matrix) is:

$$
\left\{\begin{array}{l}
w_{1}=1 \\
w_{i}=P_{1}^{\beta} \lambda^{2-i-\beta}\left(\prod_{j=2}^{i-1} e^{-Z_{j}}\right), i=2 \Lambda T
\end{array}\right.
$$

From (2) we can derive the asymptotically stable proportion of spawners in the stock PS and proportion of repeat spawners in the spawning stock $P R S$ :

$$
\begin{aligned}
& P S=1-\frac{w_{1}+\alpha^{\prime \prime} w_{2^{\prime}}}{\sum_{i=1}^{T} w_{i}}=1-\frac{1+\alpha^{\prime \prime} P_{1}^{\beta} \lambda^{-\beta}}{1+\sum_{i=2}^{T} P_{1}^{\beta} \lambda^{2-i-\beta}\left(\prod_{j=2}^{i-1} e^{-Z_{j}}\right)} \\
& P R S=1-\frac{\left(1-\alpha^{\prime \prime}\right) w_{2}+\alpha^{\prime \prime} w_{3}}{\left(1-\alpha^{\prime \prime}\right) w_{2}+\sum_{i=3}^{T} w_{i}}=1-\frac{\left(1-\alpha^{\prime \prime}\right)+\alpha^{\prime \prime} \lambda^{-1} e^{-Z_{2}}}{\left(1-\alpha^{\prime \prime}\right)+\sum_{i=3}^{T} \lambda^{2-i}\left(\prod_{j=2}^{i-1} e^{-Z_{j}}\right)}
\end{aligned}
$$


Both of them are indices of the reproductive potential of the stock. PRS might be useful for populations where maternal effects on egg production and quality are important.

\subsection{Sensitivity analyses and decomposition of fishing effects}

The sensitivities of $\lambda$ to changes in the population parameters $x_{i}, \frac{\partial \lambda}{\partial x_{i}}$, can be calculated by implicit differentiation of the characteristic equation (1) (Caswell, 1996) and are given in Appendix 1.

To compare the population parameters set in two situations with different fishing pressures (A) and (B), the changes in parameters $x_{i}^{(A)}-x_{i}^{(B)}$ are turned into their contributions to the change in population growth rate $\lambda^{(A)}-\lambda^{(B)}$. Because $\left\{x_{i}\right\}$ is a set of sufficient parameters for $\lambda$, the first order approximation of this change provides the decomposition in contributions of each parameter to the effect of fishing on $\lambda$ :

$$
\lambda^{(A)}-\left.\lambda^{(B)} \approx \sum_{i}\left(x_{i}^{(A)}-x_{i}^{(B)}\right) \frac{\partial \lambda}{\partial x_{i}}\right|_{\left(x_{i}^{(A)}+x_{i}^{(B)}\right) / 2}
$$

The partial derivatives are evaluated at the midpoint between $\left\{x_{i}^{(A)}\right\}$ and $\left\{x_{i}^{(B)}\right\}$ (Caswell, 1989a; Caswell, 1989b; Caswell, 1996). The analysis was performed both with $\left\{x_{i}\right\}=\left\{\alpha^{\prime}, \alpha^{\prime \prime}, P_{0}, P_{1}, a, b, \stackrel{\rho}{\rho}, Z\right\}$ and $\left\{x_{i}\right\}=\left\{\alpha^{\prime}, \alpha^{\prime \prime}, P_{0}, P_{1}, \stackrel{\rho}{\rho, Z}, Z, r\right.$ is considered fixed and is not a parameter of the model. The contributions of $\alpha^{\prime}$ and $\alpha^{\prime \prime}$ are summed into contribution of $\alpha$.

As the analysis can be applied to the asymptotically stable population structure, it was used to compare the contributions of mortality rates and age at maturity to changes in asympotic PS and PRS (sensitivities in Appendix 1).

\subsection{Estimating demographic parameters}

The parameters were gathered from the literature or estimated from published data. All parameters had to be estimated from data collected during a short period ( 3 to 9 years) for each situation being compared. Age at maturity, length-at-age and the fecundity-length relationship were obtained by biological sampling of commercial or scientific catches. Total mortality at age $Z_{i}(i=2 \ldots T-1)$ and $P_{1}$ were estimated by Virtual Population Analysis (VPA) (North Sea plaice), cohort analysis (Greenland halibut) or catch curve (Dover sole). For North Sea plaice, estimation of the survival from egg to recruitment $P_{0}$ was possible from time-series of recruit numbers and annual population fecundity; all population parameters being available, $\lambda$ was estimated by a numerical method from equation 1 . For the other two stocks, $\lambda$ was estimated as the mean of $N_{t+1} / N_{t}$ ( $N_{t}$ being total population size in year $\left.t\right)$ over the time-period considered. Then $P_{0}$ was estimated as the early survival that allows this population growth rate (Vaughan and Saila, 1976). 
Plaice (Pleuronectes platessa L.) has been exploited in the North Sea for several centuries, but exploitation was much lower during the second world war (Rijnsdorp, 1992). A set of population parameters is available for the immediate post-war period, as the cohorts born during the war came into exploitation. Then fishing pressure steadily increased until recent years. A recent period (19771985) is compared to the post-war (1947-49) less exploited period.

The exploitation of Dover sole (Microstomus pacificus Lockington) began off California in the forties, and the population dynamics were assessed after some years of rather heavy exploitation (1948-49) (Hagerman, 1952). In the recent period, the estimated total mortality is weaker, presumably because fishing is less intensive. Dover sole provides us with an example of the effect of decreasing fishing mortality.

The fishery for Greenland halibut (Reinhardtius hippoglossoides Walbaum) in the north-west Atlantic began in the last century and has considerably increased during the last 35 years (Morgan and Bowering, 1997; Brodie et al., 1998). The stock is declining since the mid 1980s; catches were reduced after 1995 as a result of management measures. The period before the decline (1975-80) is compared with the population minimum (1990-95). As reproduction parameters vary in space (Morgan and Bowering, 1997), the present study is concentrated on Greenland halibut in NAFO subareas 3KL.

The data and their references are provided in Appendix 2. 


\section{Results}

North Sea plaice adult mortality rates increased between 1947-49 and 1977-85, and early survival $P_{0}$ decreased, acting to reduce the population growth rate from 1.3 to 1.1 (Table 1); this was partially compensated for by a change in age at maturity and changes in length-at-age (Fig. 2). The contributions of the fecundity-length parameters are not easily readable, because $a$ and $b$ vary in opposite directions, and they have opposite contributions to the variation in $\lambda$. The alternative decomposition in fecundity at age allows to state that decrease in survival at all stages was counteracted by earlier maturity and increased fecundity (Fig.3). The contributions of changes in fecundity are the highest in the year following maturity and decrease rapidly with age. Similarly, changes in mortality rates and lengths are of the same magnitude along the life span, but their highest contribution to the change in population growth rate is at maturity (Fig. 4).

\begin{tabular}{lccc}
\hline & $\lambda$ & PS & PRS \\
\hline North Sea plaice 1947-49 & 1.310 & 0.389 & 0.510 \\
North Sea plaice 1977-85 & 1.133 & 0.621 & 0.556 \\
California Dover sole 1947-49 & 0.956 & not available & not available \\
California Dover sole 1985-91 & 0.953 & not available & not available \\
Labrador Greenland halibut 1975-80 & 0.986 & 0.0051 & 0.391 \\
Labrador Greenland halibut 1990-95 & 0.879 & 0.0057 & 0.724 \\
\hline
\end{tabular}

Table 1: Population growth rate $\lambda$ and observed proportions of spawners in the stock (PS) and repeat spawners in the spawning stock (PRS) for the populations compared.
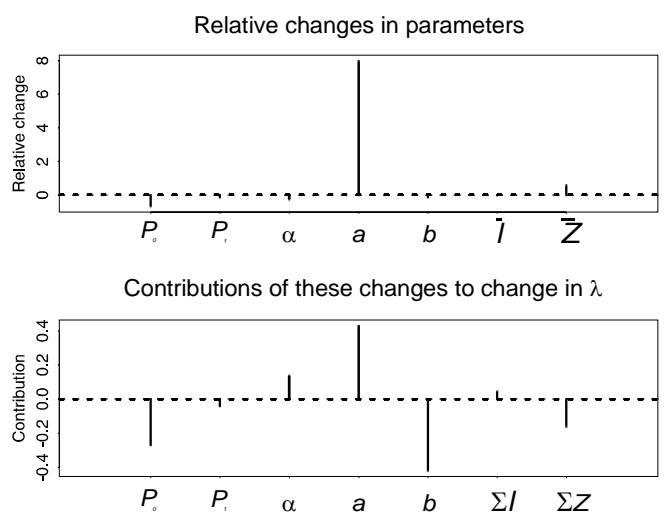

Figure 2: Relative changes in $\left\{x_{i}\right\}=\left\{\alpha, P_{0}, P_{1}, a, b, \stackrel{\rho}{\perp}, \stackrel{\rho}{Z}\right\}$ in North Sea plaice between 1947-49 and 197785 , and their contributions to change in population growth rate. 
North Sea plaice
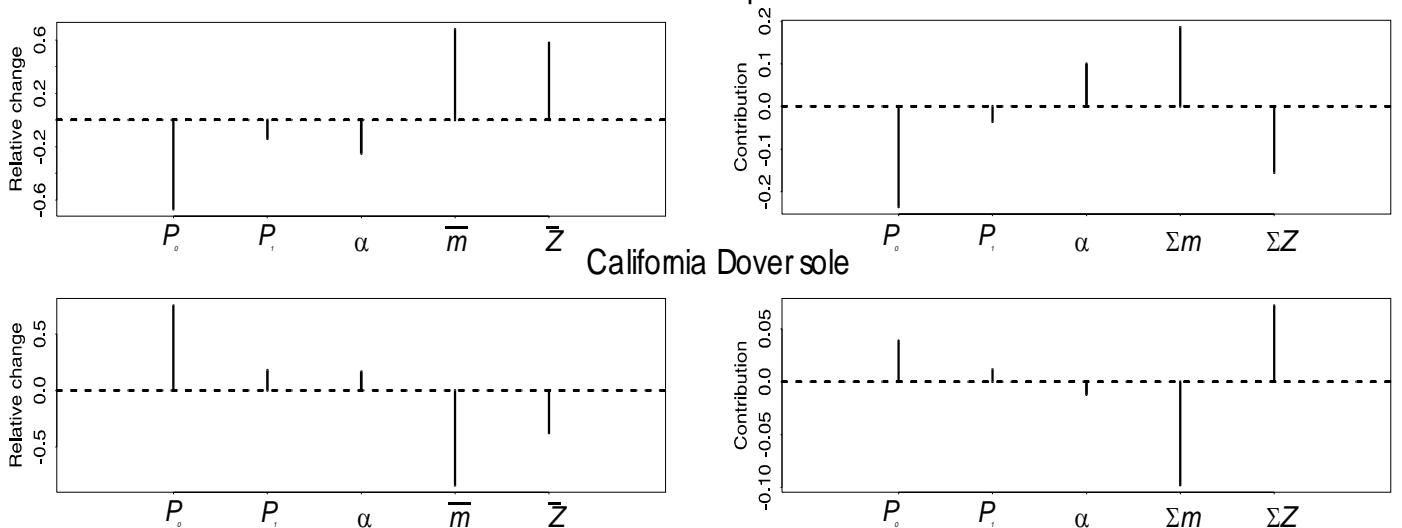

Greenland halibut

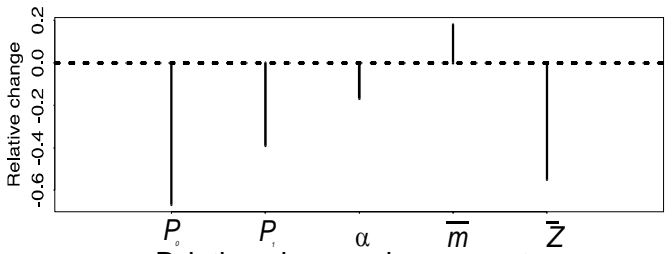

Relative changes in parameters

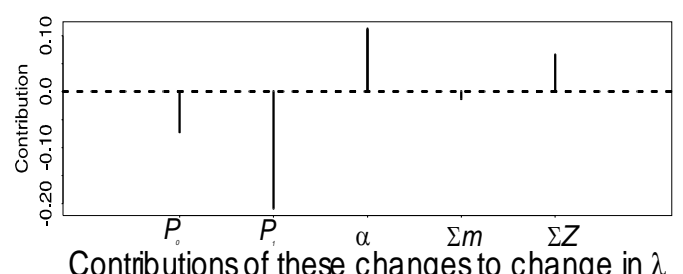

Contributions of these changes to change in $\lambda$

Figure 3: Relative changes in $\left\{x_{i}\right\}=\left\{\alpha, P_{0}, P_{1}, \stackrel{\rho}{\rho}, \underset{\Omega}{Z}\right\}$ in North Sea plaice, California Dover sole and South Labrador Greenland halibut between periods of different fishing pressures, and their contributions to change in population growth rate.
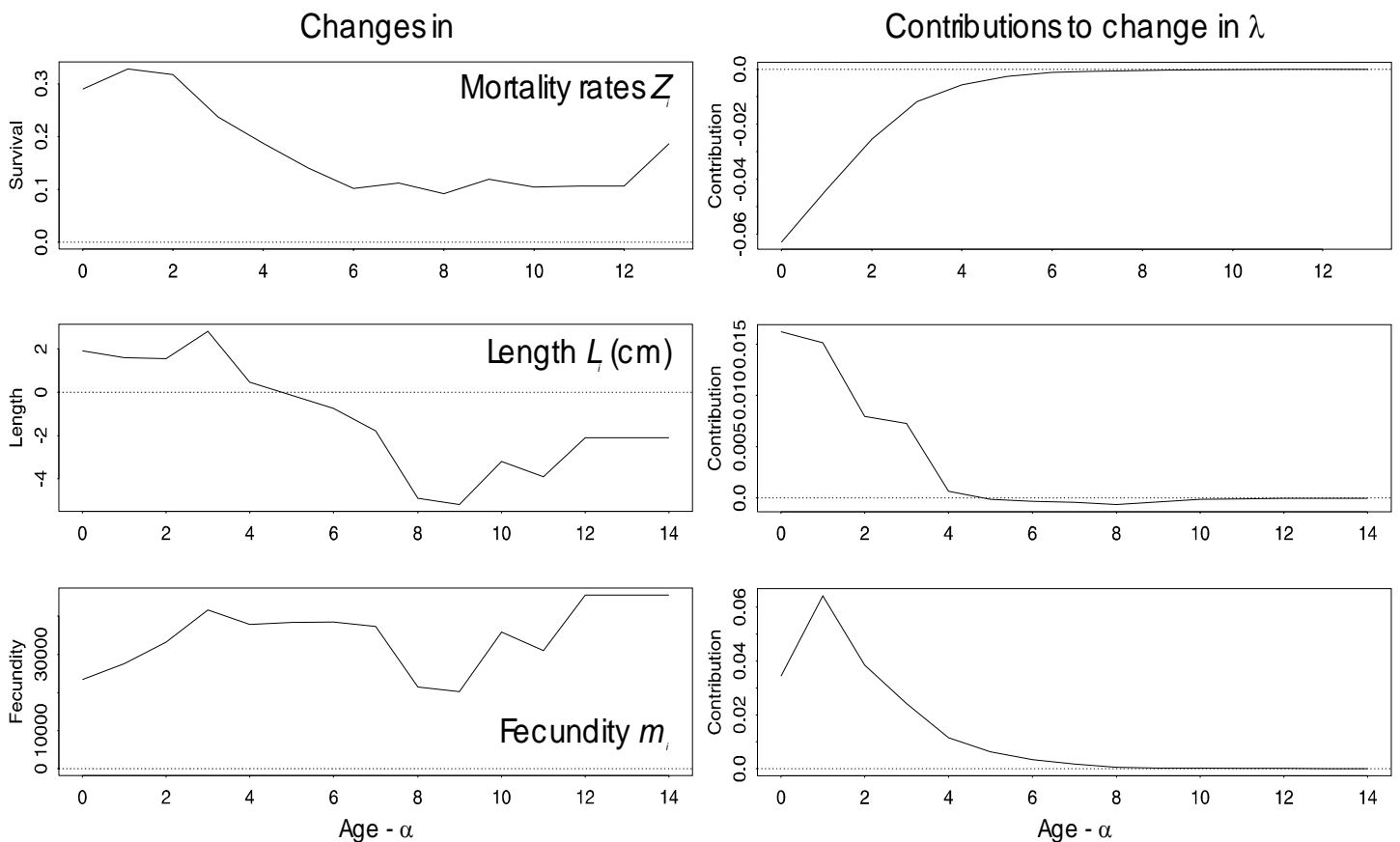

Figure 4: Changes in mortality rates at age, lengths at age and fecundity at age in North Sea plaice between 1947-49 and 1977-85, and their contributions to change in population growth rate. Age is in year since maturity. Contributions of lengths and fecundities are computed from different decompositions and cannot be summed. 
In California Dover sole, the decrease in adult mortality rates was associated with an increase in early and juvenile survival, later maturity and decreased fecundity (Fig. 3). The latter change had the highest contribution to the small change in population growth rate (Table 1).

In Labrador Greenland halibut, the increase in fishing pressure was directed against recruits and resulted in a decrease of juvenile survival, which has a high contribution to the decrease in population growth rate (Table 1, Fig. 3). This was partially compensated for by earlier maturity and a decrease in adult total mortality.

In all three populations early survival varied like adult survival and did not contribute to counteract the effects of fishing mortality.

The compositions of the stock in non spawners / first-time / repeat spawners differs among life history strategies (Table 2). Observed PS and PRS are of the order of magnitude of their asymptotic value. They are also similarly affected by fishing (Tables 1 and 2). The proportion of spawners in the stock is sensitive to changes both in juvenile and adult mortality, but these were compensated for by earlier maturity; changes in the proportion of repeat spawners in the spawning stock are due to adult mortality only (Table 2).

\begin{tabular}{lccc}
\hline & North Sea plaice & Dover sole & Greenland halibut \\
\hline Change in PS & $0.504-0.482=0.022$ & $0.891-0.782=0.109$ & $0.021-0.013=0.008$
\end{tabular}

Contributions to this change:

\begin{tabular}{lccc}
$\alpha$ & 0.0750 & -0.0232 & 0.0241 \\
$\boldsymbol{P}_{1}$ & -0.0263 & 0.0220 & -0.0448 \\
$\Sigma Z_{i}$ & -0.1225 & 0.1260 & 0.0112 \\
\hline Change in PRS & $0.339-0.51=-0.171$ & $0.893-0.779=0.114$ & $0.688-0.057=0.6308$
\end{tabular}

Contributions to this change:
$\Sigma Z_{i}$
$-0.276$
0.110
0.426

Table 2: Changes in the asymptotic proportion of spawners in the stock (PS) and proportion of repeat spawners in the spawning stock (PRS), and contribution of the parameters to these changes. 


\section{Discussion}

In all three populations examined, change in age at maturity significantly contributed to counteract the effect of fishing mortality on population growth rate. It responded both to juvenile and adult total mortality. It also had a potential to reverse in Dover sole, although the contribution of this reversal to population stability was not the most important. This trait has long been found to be affected by fishing (e.g. Schaffer and Elson, 1975; Beacham, 1983; Haug and Tjemsland, 1986; Jorgensen, 1990; Rijnsdorp, 1992; Rochet, 1998), and on this basis, Trippel (1995) suggested to use it as an indicator of population state. By a different modelling approach, it has been shown that age at maturity is an important component of the recovery time of depleted populations (Myers et al., 1997). The present results show that it is an important component of population response to fishing, hence a potential index of viability.

Whereas the proportion of spawners in the stock was not affected by fishing, the proportion of repeat spawners in the spawning stock may be an index of exploitation patterns and intensity. Sensitivity of the former to both juvenile and adult mortality is counteracted by changes in age at maturity. The latter is sensitive to adult mortality and the only potential way to compensate for it is the proportion $\alpha^{\prime \prime}$ of fish that do not reproduce at age $\alpha^{\prime}$. Management policies letting some individuals spawn several times, and an appropriate index, may be valuable for species with maternal effects.

Changes in length are not consistent between the three stocks examined here. This is partly because length is at "age since maturity" and not "age since birthday" in the model. Earlier maturity can result in smaller size at stage, even if growth is faster in exploited populations. In addition, these changes have a weak contribution to the variations in population growth rate.

The parameters $a$ and $b$ of the fecundity-length relationship vary in opposite directions, at least partly because they are statistically correlated as they are estimated together from a linear regression. In all three cases both have a significant contribution to the variation in population growth rate, but always opposite. An increase in $a$ has a positive contribution for North sea plaice and negative for Greenland halibut, and a decrease in $a$ has a negative contribution for Dover sole (reverse all for $b$ ). In addition, the expression of the model in $\left\{x_{i}\right\}=\left\{\alpha^{\prime}, \alpha^{\prime \prime}, P_{0}, P_{1}, a, b, \stackrel{\rho}{L}, \underset{Z}{Z}\right\}$ like in equation (1) is far from linear in $a$, $b$ and $L_{i}$, and the linear approximation of the variation in $\lambda$ (equation 4 ) does not hold as soon as the changes in these traits are not small. For all these reasons, these parameters cannot be recommended as indices.

The combination of length at age and the fecundity-length parameters into fecundity at age yields more consistent results. In North sea plaice as well as in Dover sole, changes in fecundity have the highest contribution to counteracting the effects of changes in mortality. In Greenland halibut, earlier maturity associated with increased juvenile mortality results in smaller spawners, which spawn less eggs; even an increase in $b$ does not compensate for this. Therefore the overall contribution of 
fecundity to the decrease in $\lambda$ is slightly negative. This might suggest that the response to exploitation differs when juveniles are targeted. Additional adult mortality results in earlier maturity and higher fecundity, whereas increased juvenile mortality is compensated for only by maturing earlier. This is in accordance with the theoretical prediction that increased mortality on individuals younger than any age $i$ selects for lower rates of reproduction at $i$, whereas additional mortality on individuals older than or equal to $i$ selects for greater rates of reproduction (Law, 1979) (just set $i=$ age at maturity). Hence fecundity might be an index of at least adult exploitation, but it is not very easy to measure. An index simpler than the list of fecundity at each age may be useful, but is still to be found. Fecundity in the year of maturity may have an important contribution to the population fecundity in heavily exploited stocks, but it is not easy to determine when all individuals do not mature at the same age in the population; in addition, the contribution of first-time spawners should be weighted by the lower survival of their offspring due to maternal effects.

An interesting result is the contribution of early survival $P_{0}$, which never counteracts the effect of fishing mortality. This is not in accordance with previous stock-recruitment theory, which assumed that density-dependence in fish populations occurred mainly during egg- and larval stages (Ricker, 1954; Beverton and Holt, 1957). The potential of adults and juveniles to adjust for fishing may have been underestimated in the past. On the other hand, $P_{0}$ is the most difficult parameter to estimate, and we probably lack precision on it.

These results are dependent on the particular combination of parameters used in each situation. Changing their values leads to different sensitivities, hence different decompositions. The confidence in the data for North Sea plaice is high because all parameters were carefully determined on the basis of extensive sampling, and checked by different authors. By contrast, the 1947-49 parameter set for Dover sole relies on sampling of commercial catches during 16 months and a few scientific samples, all published in a single paper; the precision is probably lower, although the consistency of the results gives additional confidence. The precision on Greenland halibut data is intermediate. Whereas the qualitative conclusions probably will hold, the sensitivity of the results to the uncertainty on parameters should be investigated. This would require variance estimates for each of the parameters used, which are generally not published.

The model may be refined in several ways, for example to account for more complex maturity ogives, or for maternal effects. Also the decomposition of the variation in $\lambda$ may be expanded to include second order terms (Caswell, 1996). The gain to be expected from these refinements is to be weighted by the precision we can reasonably hope on the parameters.

The weakness of this model is its deterministic nature. Recruitment is known to fluctuate widely in fish populations, mainly under environmental influence. This may be described in a stochastic version by letting early survival $P_{0}$ for example be a random variable. Methods have been developed to analyse matrix models with random vital rates (Tuljapurkar, 1990). The stochastic growth rate is 
always lower than the deterministic growth rate of the average matrix (Tuljapurkar, 1997), thus we expect the present results to be changed. The price to pay is the loss of analytical formulae. However, sensitivities can be obtained by simulation (Benton and Grant, 1996). They require estimates of variation in the parameters and of their covariation. Although difficult, this framework is promising because it would allow calculations of extinction risks associated with any parameter set.

Indices other than population biomass have been used in contexts where abundance estimation is difficult or too costly, for example in small-scale freshwater fisheries. They include indices of population size structure like the Proportional Stock Density (PSD: number of quality-size fish divided by the number of stock-size fish: Carline et al., 1984) and condition indices like the Relative Weight Index (Murphy et al., 1991). These authors stress that they bring useful information but should not be used alone to evaluate programs or assess populations. They also emphasize the need to clarify the relation of such indices to population dynamics. I believe that the present framework is suitable for this kind of objectives, provided these indices are turned from growth-oriented indices into reproduction-oriented indices; this is an essential criterion for viability indices. PSD can be turned into PS and PRS; condition indices, which have also been proposed for marine fish populations (Lambert and Dutil, 1997), can probably be related to fecundity (Marshall et al., 1998; Marshall and Frank, 1999). These indices are both sensitive measures of the reproductive potential of the population, and less costly than population abundance estimates. Such indices may find applications in fisheries where management has to be done in data-poor environments, like tropical fisheries (Johannes, 1998; Jennings et al., 1999).

The present framework will also be suitable to establish reference points. The method allows to compute criteria for the maximisation of $\lambda$ under a given set of parameters and management objectives, and answer questions like "What is the desirable (or undesirable) proportion of repeat spawners in the spawning stock?", and "Which exploitation pattern will most affect the proportion of repeat spawners?". Moreover, the stochastic version may allow to set undesirable risks of extinction and the criteria to avoid them.

I conclude that age at maturity, PRS and some measure of fecundity may be useful indices of population sustainability. The knowledge missing to continue the analysis of their relevance is mainly the estimation of early survival $P_{0}$ and of its variance on the population scale. 


\section{Appendix 1: Sensitivities}

Sensitivities of the population growth rate to the population parameters:

$$
\begin{aligned}
& \frac{\partial \lambda}{\partial \alpha^{\prime}}=-\frac{\lambda^{\alpha^{\prime}} \ln \lambda-P_{0} P_{1}^{\beta} \ln P_{1}\left(\left(1-\alpha^{\prime \prime}\right) a L_{2}^{b}-\sum_{i=3}^{T} a L_{i}^{b} \lambda^{2-i} \prod_{j=2}^{i-1} e^{-Z_{j}}\right)}{\alpha^{\prime} \lambda^{\alpha^{\prime}-1}+P_{0} P_{1}^{\beta} \sum_{i=2}^{T} a L_{i}^{b}(i-2) \lambda^{1-i} \prod_{j=2}^{i-1} e^{-Z_{j}}} \\
& \frac{\partial \lambda}{\partial \alpha^{\prime \prime}}=-\frac{\alpha^{\prime \prime} a L_{2}^{b} P_{0} P_{1}^{\beta}}{\alpha^{\prime} \lambda^{\alpha^{\prime}-1}+P_{0} P_{1}^{\beta} \sum_{i=2}^{T} a L_{i}^{b}(i-2) \lambda^{1-i} \prod_{j=2}^{i-1} e^{-Z_{j}}} \\
& \frac{\partial \lambda}{\partial P_{0}}=-\frac{\alpha^{\prime \prime} a L_{2}^{b} P_{1}^{\beta}-P_{1}^{\beta} \sum_{i=2}^{T} a L_{i}^{b} \lambda^{2-i} \prod_{j=2}^{i-1} e^{-Z_{j}}}{\alpha^{\prime} \lambda^{\alpha^{\prime}-1}+P_{0} P_{1}^{\beta} \sum_{i=2}^{T} a L_{i}^{b}(i-2) \lambda^{1-i} \prod_{j=2}^{i-1} e^{-Z_{j}}} \\
& \frac{\partial \lambda}{\partial P_{1}}=-\frac{\alpha^{\prime \prime} \beta a L_{2}^{b} P_{0} P_{1}^{\beta-1}-\beta P_{1}^{\beta-1} \sum_{i=2}^{T} a L_{i}^{b} \lambda^{2-i} \prod_{j=2}^{i-1} e^{-Z_{j}}}{\alpha^{\prime} \lambda^{\alpha^{\prime}-1}+P_{0} P_{1}^{\beta} \sum_{i=2}^{T} a L_{i}^{b}(i-2) \lambda^{1-i} \prod_{j=2}^{i-1} e^{-Z_{j}}} \\
& \frac{\partial \lambda}{\partial a}=-\frac{\alpha^{\prime \prime} L_{2}^{b} P_{0} P_{1}^{\beta}-P_{0} P_{1}^{\beta} \sum_{i=2}^{T} L_{i}^{b} \lambda^{2-i} \prod_{j=2}^{i-1} e^{-Z_{j}}}{\alpha^{\prime} \lambda^{\alpha^{\prime}-1}+P_{0} P_{1}^{\beta} \sum_{i=2}^{T} a L_{i}^{b}(i-2) \lambda^{1-i} \prod_{j=2}^{i-1} e^{-Z_{j}}} \\
& \frac{\partial \lambda}{\partial b}=-\frac{\alpha^{\prime \prime} a L_{2}^{b} \ln \left(L_{2}\right) P_{0} P_{1}^{\beta}-P_{0} P_{1}^{\beta} \sum_{i=2}^{T} L_{i}^{b} \ln \left(L_{i}\right) \lambda^{2-i} \prod_{j=2}^{i-1} e^{-Z_{j}}}{\alpha^{\prime} \lambda^{\alpha^{\prime}-1}+P_{0} P_{1}^{\beta} \sum_{i=2}^{T} a L_{i}^{b}(i-2) \lambda^{1-i} \prod_{j=2}^{i-1} e^{-Z_{j}}} \\
& \frac{\partial \lambda}{L_{2}}=-\frac{\left(\alpha^{\prime \prime}-1\right) a b L_{2}^{b-1} P_{0} P_{1}^{\beta}}{\alpha^{\prime} \lambda^{\alpha^{\prime}-1}+P_{0} P_{1}^{\beta} \sum_{i=2}^{T} a L_{i}^{b}(i-2) \lambda^{1-i} \prod_{j=2}^{i-1} e^{-Z_{j}}} \\
& \frac{\partial \lambda}{\partial L_{k}}=-\frac{a b L_{k}^{b-1} P_{0} P_{1}^{\beta} \prod_{j=2}^{k-1} e^{-Z_{j}}}{\alpha^{\prime} \lambda^{\alpha^{\prime}-1}+P_{0} P_{1}^{\beta} \sum_{i=2}^{T} a L_{i}^{b}(i-2) \lambda^{1-i} \prod_{j=2}^{i-1} e^{-Z_{j}}}, k=3 \Lambda T \\
& \frac{\partial \lambda}{\partial Z_{k}}=-\frac{P_{0} P_{1}^{\beta} \sum_{i=k+1}^{T} a L_{i}^{b} \lambda^{1-i} \prod_{j=2}^{i-1} e^{-Z_{j}}}{\alpha^{\prime} \lambda^{\alpha^{\prime}-1}+P_{0} P_{1}^{\beta} \sum_{i=2}^{T} a L_{i}^{b}(i-2) \lambda^{1-i} \prod_{j=2}^{i-1} e^{-Z_{j}}}, k=2 \Lambda T-1
\end{aligned}
$$


Sensitivities of the proportion of spawners in the stock, $P S$, to the population parameters:

$$
\begin{aligned}
& \frac{\partial P S}{\partial \alpha^{\prime}}=\frac{\left(P_{1} / \lambda\right)^{\beta}\left(\ln \lambda-\ln P_{1}\right)\left(\alpha-\sum_{i=2}^{T} \lambda^{2-i} \prod_{j=2}^{i-1} e^{-Z_{j}}\right)}{\left(1+\left(P_{1} / \lambda\right)^{\beta} \sum_{i=2}^{T} \lambda^{2-i} \prod_{j=2}^{i-1} e^{-Z_{j}}\right)^{2}} \\
& \frac{\partial P S}{\partial \alpha^{\prime \prime}}=-\frac{\left(P_{1} / \lambda\right)^{\beta}}{1+\left(P_{1} / \lambda\right)^{\beta} \sum_{i=2}^{T} \lambda^{2-i} \prod_{j=2}^{i-1} e^{-Z_{j}}} \\
& \frac{\partial P S}{\partial P_{1}}=-\frac{\beta P_{1}^{\beta-1} \lambda^{-\beta}\left(\alpha^{\prime \prime}-\sum_{i=2}^{T} \lambda^{2-i} \prod_{j=2}^{i-1} e^{-Z_{j}}\right)^{2}}{\left(1+\left(P_{1} / \lambda\right)^{\beta} \sum_{i=2}^{T} \lambda^{2-i} \prod_{j=2}^{i-1} e^{-Z_{j}}\right)^{2}} \\
& \frac{\partial P S}{\partial Z_{k}}=-\frac{\left(P_{1} / \lambda\right)^{\beta}\left(1+\alpha{ }^{\prime \prime}\left(P_{1} / \lambda\right)^{\beta}\right) \sum_{i=k+1}^{T} \lambda^{2-i} \prod_{j=2}^{i-1} e^{-Z_{j}}}{\left(1+\left(P_{1} / \lambda\right)^{\beta} \sum_{i=2}^{T} \lambda^{2-i} \prod_{j=2}^{i-1} e^{-Z_{j}}\right)^{2}}, k=2 \Lambda T-1
\end{aligned}
$$

Sensitivities of the proportion of repeat spawners in the spawning stock, $P R S$, to the population parameters:

$$
\begin{aligned}
& \frac{\partial P R S}{\partial \alpha^{\prime \prime}}=\frac{1-e^{-Z_{2}} / \lambda}{1-\alpha^{\prime \prime}+\sum_{i=3}^{T} \lambda^{2-i} \prod_{j=2}^{i-1} e^{-Z_{j}}}-\frac{1-\alpha^{\prime \prime}+\alpha^{\prime \prime} e^{-Z_{2}} / \lambda}{\left(1-\alpha^{\prime \prime}+\sum_{i=3}^{T} \lambda^{2-i} \prod_{j=2}^{i-1} e^{-Z_{j}}\right)^{2}} \\
& \frac{\partial P R S}{\partial Z_{2}}=\frac{\alpha^{\prime \prime} e^{-Z_{2} / \lambda}}{1-\alpha^{\prime \prime}+\sum_{i=3}^{T} \lambda^{2-i} \prod_{j=2}^{i-1} e^{-Z_{j}}}-\frac{\left(1-\alpha^{\prime \prime}+\alpha^{\prime \prime} e^{-Z_{2}} / \lambda\right) \sum_{i=3}^{T} \lambda^{2-i} \prod_{j=2}^{i-1} e^{-Z_{j}}}{\left(1-\alpha^{\prime \prime}+\sum_{i=3}^{T} \lambda^{2-i} \prod_{j=2}^{i-1} e^{-Z_{j}}\right)^{2}} \\
& \frac{\partial P R S}{\partial Z_{k}}=-\frac{\left(1-\alpha^{\prime \prime}+\alpha^{\prime \prime} e^{-Z_{2}} / \lambda\right) \sum_{i=k+1}^{T} \lambda^{2-i} \prod_{j=2}^{i-1} e^{-Z_{j}}}{\left(1-\alpha^{\prime \prime}+\sum_{i=3}^{T} \lambda^{2-i} \prod_{j=2}^{i-1} e^{-Z_{j}}\right)^{2}}, k=2 \Lambda T-1
\end{aligned}
$$




\section{Appendix 2: Summary of population parameters used in the study}

\section{A) North Sea plaice}

\begin{tabular}{|c|c|c|c|c|c|}
\hline \multirow{2}{*}{$\begin{array}{c}\text { Paramete } \\
\text { r }\end{array}$} & \multirow[t]{2}{*}{ Definition } & \multicolumn{2}{|c|}{ Values } & \multicolumn{2}{|c|}{ Data sources } \\
\hline & & 1947-49 (low) & 1977-85 (high) & $1947-49$ & $1977-85$ \\
\hline$r$ & $\begin{array}{l}\text { Age at recruitment } \\
\text { (years) }\end{array}$ & & & & \\
\hline$P_{0}$ & $\begin{array}{l}\text { Probability of surviving } \\
\text { from egg to recruitment }\end{array}$ & $7.1510^{-5}$ & $2.3710^{-5}$ & $\begin{array}{l}\text { (Simpson, 1959; } \\
\text { Bannister, 1977) }\end{array}$ & $\begin{array}{l}\text { (Anonymous, } \\
1998 \text { ) }\end{array}$ \\
\hline$P_{1}$ & $\begin{array}{l}\text { Probability of surviving } \\
\text { to next year before } \\
\text { maturity }\end{array}$ & 0.883 & 0.649 & $\begin{array}{l}\text { (Bannister, } \\
\text { 1977) }\end{array}$ & $\begin{array}{l}\text { (Anonymous, } \\
1998)\end{array}$ \\
\hline$\alpha$ & Age at maturity (years) & 4 & 3 & (Simpson, 1959) & $\begin{array}{l}\text { (Anonymous, } \\
1998)\end{array}$ \\
\hline $\begin{array}{l}a \\
b\end{array}$ & $\begin{array}{l}\text { Parameters of the } \\
\text { fecundity-length } \\
\text { relationship } m_{i}=a L_{i}^{b}\end{array}$ & $\begin{array}{l}0.374 \\
3.169\end{array}$ & $\begin{array}{l}3.356 \\
2.732\end{array}$ & $\begin{array}{l}\text { (Rijnsdorp, } \\
\text { 1991) }\end{array}$ & $\begin{array}{l}\text { (Rijnsdorp, } \\
\text { 1991) }\end{array}$ \\
\hline$L_{i}$ & $\begin{array}{l}\text { Length at age } i(\mathrm{~cm}), \\
i=\alpha \ldots T\end{array}$ & $\begin{array}{l}29.032 .035 .036 .040 .0 \\
42.044 .047 .051 .052 .0 \\
52.553 .053 .053 .053 .0\end{array}$ & $\begin{array}{l}30.933 .636 .538 .840 .5 \\
41.943 .345 .246 .146 .8 \\
49.349 .150 .950 .950 .9\end{array}$ & $\begin{array}{l}\text { (Bannister, } \\
\text { 1977) }\end{array}$ & $\begin{array}{l}\text { (Anonymous, } \\
1998)\end{array}$ \\
\hline$Z_{i}$ & $\begin{array}{l}\text { Rate of total mortality at } \\
\text { age } i, i=\alpha \ldots T-1\end{array}$ & 0.3 & $\begin{array}{c}0.590 .630 .620 .540 .49 \\
0.440 .400 .410 .390 .42 \\
0.400 .410 .410 .49\end{array}$ & $\begin{array}{l}\text { (Bannister, } \\
\text { 1977) }\end{array}$ & $\begin{array}{l}\text { (Anonymous, } \\
1998 \text { ) }\end{array}$ \\
\hline
\end{tabular}




\section{B) California Dover sole (Eureka area)}

\begin{tabular}{|c|c|c|c|c|}
\hline Paramete & \multicolumn{2}{|l|}{ Values } & \multicolumn{2}{|c|}{ Data sources } \\
\hline & 1947-49 (high) & 1985-91 (low) & $1947-49$ & $1985-91$ \\
\hline$r$ & 5 & & & \\
\hline$P_{0}$ & $210^{-06}$ & $3.510^{-06}$ & & \\
\hline$P_{1}$ & 0.756 & 0.892 & (Hagerman, 1952) & (Turnock et al., 1994) \\
\hline$\alpha$ & 6 & 7 & (Hagerman, 1952) & (Hunter et al., 1992) \\
\hline$a$ & 0.000248 & 0.479 & (Hagerman, 1952) & (Hunter et al., 1992) \\
\hline$b$ & 5.2 & 3.02 & & \\
\hline \multirow[t]{4}{*}{$L_{i}$} & 37.940 .142 .144 .045 .747 .348 .7 & 31.032 .433 .634 .735 .736 .7 & (Hagerman, 1952) & (Hunter et al., 1990) \\
\hline & 50.151 .352 .553 .554 .555 .456 .3 & 37.5632838 .439 .139 .840 .441 .0 & & \\
\hline & 57.057 .758 .459 .059 .660 .160 .5 & 41.542 .042 .442 .843 .243 .543 .9 & & \\
\hline & 61.061 .461 .8 & 44.144 .444 .744 .945 .1 & & \\
\hline \multirow[t]{4}{*}{$Z_{i}$} & 0.280 & 0.130 .140 .140 .150 .150 .150 .16 & (Hagerman, 1952) & (Turnock et al., 1994) \\
\hline & & 0.160 .140 .150 .160 .170 .190 .15 & & \\
\hline & & 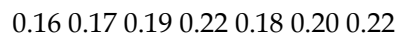 & & \\
\hline & & 0.250 .30 & & \\
\hline
\end{tabular}

\section{C) South Labrador Greenland halibut}

\begin{tabular}{|c|c|c|c|c|}
\hline \multirow{2}{*}{$\begin{array}{c}\text { Paramete } \\
\text { r }\end{array}$} & \multicolumn{2}{|c|}{ Values } & \multicolumn{2}{|c|}{ Data sources } \\
\hline & 1975-80 (low) & 1990-95 (high) & $1975-80$ & 1990-95 \\
\hline$r$ & 5 & & & \\
\hline$P_{0}$ & 0.003 & 0.001 & & \\
\hline$P_{1}$ & 0.529 & 0.323 & (Brodie et al., 1998) & (Brodie et al., 1998) \\
\hline$\alpha$ & 12 & 10 & (Bowering, 1983) & $\begin{array}{l}\text { (Morgan and } \\
\text { Bowering, 1997) }\end{array}$ \\
\hline$a$ & 0.0312 & 0.0026 & (Bowering, 1980) & (Junquera et al., \\
\hline$b$ & 3.082 & 3.7 & & 1998) \\
\hline$L_{i}$ & $\begin{array}{c}77.579 .7581 .7584 .2584 .986 .1 \\
87.288 .088 .7\end{array}$ & $\begin{array}{c}64.068 .973 .878 .483 .787 .691 .4 \\
91.994 .5\end{array}$ & (Bowering, 1983) & (de Cárdenas, 1996) \\
\hline$Z_{i}$ & 0.990 .661 .021 .01 .01 .01 .01 .0 & 0.434 & (Brodie et al., 1998) & (Brodie et al., 1998) \\
\hline
\end{tabular}




\section{References}

Anonymous, 1998. Report of the working group on the assessment of demersal stocks in the North Sea and Skagerrak. ICES C.M. 1998 / Assess: 7, 702 pp.

Bannister, R. C. A., 1977. North Sea Plaice. In: J. A. Gulland (Editor) Fish population dynamics. Wiley, London, pp 243-282.

Beacham, T. D., 1983. Variability in median size and age at sexual maturity of Atlantic Cod, Gadus morhua, on the Scotian Shelf in the Northwest Atlantic Ocean. Fishery Bulletin, 81: 303-321.

Beamish, R. J., and McFarlane, G. A., eds. 1989. Effects of ocean variability on recruitment and an evaluation of parameters used in stock assessment models. Canadian Special Publications of Fisheries and Aquatic Sciences, 108, Department of Fisheries and Oceans, Ottawa.

Benton, T. G., and Grant, A., 1996. How to keep fit in the real world: elasticity analyses and selection pressures on life histories in a variable environment. American naturalist, 147: 115-139.

Beverton, R. J. H., and Holt, S. J., 1957. On the dynamics of exploited fish populations. Fishery Investigations, Series II, 19, Her Majesty's Stationery Office, London.

Beyer, J. E., 1989. Recruitment stability and survival - simple size-specific theory with examples from the early life dynamics of marine fish. Dana, 7: 45-147.

Bowering, W. R., 1980. Fecundity of Greenland Halibut, Reinhardtius hippoglossoides (Walbaum), from Southern Labrador and Southeastern Gulf of St Lawrence. Journal of Northwest Atlantic Fishery Science, 1: 39-43.

Bowering, W. R., 1983. Age, growth, and sexual maturity of Greenland Halibut, Reinhardtius hippoglossoides (Walbaum), in the Canadian Northwest Atlantic. Fishery Bulletin, 81: 599-611.

Brodie, W. B., Bowering, W. R., Power, D., and Orr, D., 1998. An assessment of Greenland halibut in NAFO subarea 2 and divisions 3KLMNO. NAFO SCR Doc 98/47, N3038, 38 pp.

Buckley, L. J., Smigielski, A. S., Halavik, T. A., Caldarone, E. M., Burns, B. R., and Laurence, G. C., 1991. Winter flounder Pseudopleuronectes americanus reproductive success. II. Effects of spawning time and female size on size, composition and viability of eggs and larvae. Marine Ecology Progress Series, 74: 125-135.

Carline, R. F., Johnson, B. L., and Hall, T. J., 1984. Estimation and interpretation of proportional stock density for fish populations in Ohio impoundments. North American Journal of Fisheries Management, 4: 139-154.

Caswell, H., 1982. Stable population structure and reproductive value for populations with complex life cycles. Ecology (New York), 63: 1223-1231.

Caswell, H., 1989a. Analysis of life table response experiments. I. Decomposition of effects on population growth rate. Ecological Modelling, 46: 221-237.

Caswell, H., 1989b. Matrix population models. Construction, analysis, and interpretation. Sinauer, Sunderland, Massachusetts,

Caswell, H., 1996. Analysis of life table response experiments. II. Alternative parameterizations for size- and stage-structured models. Ecological Modelling, 88: 73-82.

de Cárdenas, E., 1996. The females ratio by length as an indicator of sexual differences in mortality of Greenland halibut (Reinhardtius hippoglossoides) at ages 8+. NAFO SCR Doc. 96/35, N2710, 10 pp.

Hagerman, F. B., 1952. The biology of the Dover sole Microstomus pacificus (Lockington). California Fish and Game, 85: 1-48. 
Haug, R., and Tjemsland, J., 1986. Changes in size- and age-distributions and age at sexual maturity in Atlantic halibut, Hippoglossus hippoglossus, caught in North Norwegian waters. Fisheries Research, 4: 145-155.

Hoenig, J. M., Pepin, P., and Lawing, W. D., 1990. Estimating relative survival rate for two groups of larval fishes from field data: do older larvae survive better than young? Fishery Bulletin, 88: 485-491.

Horwood, J. W., Bannister, R. C. A., and Howlett, G. J., 1986. Comparative fecundity of North Sea plaice (Pleuronectes platessa L.). Proceedings of the Royal Society of London B, Biological Sciences, 228: 401-431.

Hunter, J. R., Butler, J. L., Kimbrell, C., and Lynn, E. A., 1990. Bathymetric patterns in size, age, sexual maturity, water content, and caloric density of Dover sole, Microstomus pacificus. CalCOFI Report, 31: 132-144.

Hunter, J. R., Macewicz, B. J., Chyan-huei, L., N., and Kimbrell, C. A., 1992. Fecundity, spawning, and maturity of female Dover sole, Microstomus pacificus, with an evaluation of assumptions and precision. Fishery Bulletin, U.S., 90: 101-128.

Hutchings, J. A., and Myers, R. A., 1993. Effect of age on the seasonality of maturation and spawning of Atlantic cod, Gadus morhua, in the Northwest Atlantic. Canadian Journal of Fisheries and Aquatic Sciences, 50: 2468-2474.

Hutchings, J. A., and Myers, R. A., 1994. What can be learned from the collapse of a renewable resource? Atlantic cod, Gadus morhua, of Newfoundland and Labrador. Canadian Journal of Fisheries and Aquatic Sciences, 51: 2126-2146.

Jennings, S., Reynolds, J. D., and Polunin, N. V., 1999. Predicting the vulnerability of tropical reef fishes to exploitation with phylogenies and life histories. Conservation biology, 13: 1-11.

Johannes, R. E., 1998. The case for data-less marine resource management: examples from tropical nearshore finfisheries. Tree, 13: $243-246$.

Jorgensen, T., 1990. Long-term changes in age at sexual maturity of Northeast Arctic cod (Gadus morhua L.). Journal du Conseil international pour l'Exploration de la Mer, 46: 235-248.

Junquera, S., Román, E., Paz, X., and Ramilo, G., 1998. Changes in Greenland halibut growth, condition and fecundity in the Northwest Atlantic (Flemish Pass, Flemish Cap and Southern Grand Bank). NAFO SCR Doc 98/95, N3096, 13 pp.

Katsukawa, T., 1997. Introduction of spawning potential: improvement in the threshold management theory. Reviews in Fish Biology and Fisheries, 7: 285-289.

Koslow, J. A., 1992. Fecundity and the stock-recruitment relationship. Canadian Journal of Fisheries and Aquatic Sciences, 49: 210-217.

Lambert, T. C., 1990. The effect of population structure on recruitment in herring. Journal du Conseil international pour l'Exploration de la Mer, 47: 249-255.

Lambert, Y., and Dutil, J.-D., 1997. Can simple condition indices be used to monitor and quantify seasonal changes in the energy reserves of Atlantic cod (Gadus morhua)? Canadian Journal of Fisheries and Aquatic Sciences, 54 (Suppl. 1): 104112.

Law, R., 1979. Optimal life histories under age-specific predation. The American Naturalist, 114: 399-417.

Leaman, B. M., 1986. Incorporating reproductive value into Pacific ocean perch management. International Rockfish Symposium. pp 355-368.

MacKenzie, B. R., Tomkiewicz, J., Köster, F., and Nissling, A., 1998. Quantifying and disaggregating the spawner effect: Incorporating stock structure, spatial distribution and female influences into estimates of annual population egg production. ICES CM 1998/BB: 11, 23.

Mann, R. H. K., and Mills, C. A., 1979. Demographic aspects of fish fecundity. In: P. J. Miller (Editor) Fish phenology: anabolic adaptiveness in teleosts. Academic Press, London, pp 161-177. 
Marshall, C. T., and Frank, K. T., 1999. The effect of interannual variation in growth and condition on haddock recruitment. Canadian Journal of Fisheries and Aquatic Sciences, 56: 347-355.

Marshall, C. T., Kjesbu, O. S., Yaragina, N. A., Solemdal, P., and Ulltang, Ø., 1998. Is spawner biomass a sensitive measure of the reproductive and recruitment potential of Northeast Arctic cod? Canadian Journal of Fisheries and Aquatic Sciences, 55: 1766-1783.

Marteinsdottir, G., and Thorarinsson, K., 1998. Improving the stock-recruitment relationship in Icelandic cod (Gadus morhua L.) by including age diversity of spawners. Canadian Journal of Fisheries and Aquatic Sciences, 55: 1372-1377.

Morgan, M. J., and Bowering, W. R., 1997. Temporal and geographic variation in maturity at length and age of Greenland halibut (Reinhardtius hippoglossoides) from the Canadian north-west Atlantic with implications for fisheries management. ICES Journal of marine Science, 54: 875-885.

Murawski, S. A., Rago, P. J., and Trippel, E. A., 1998. Impacts of demographic variation in spawning success on reference points for fishery management. 5th NMFS Stock Assessment Workshop. pp 77-85.

Murphy, B. R., Willis, D. W., and Springer, T. A., 1991. The Relative Weight Index in fisheries management: status and needs. Fisheries, 16: 30-38.

Myers, R. A., Mertz, G., and Fowlow, P. S., 1997. Maximum population growth rates and recovery times for Atlantic cod, Gadus morhua. Fishery Bulletin, 95: 762-772.

Ricker, W. E., 1954. Stock and recruitment. Journal of the Fisheries Research Board of Canada, 11: 559-623.

Rijnsdorp, A. D., 1991. Changes in fecundity of female North Sea plaice (Pleuronectes platessa L.) between three periods since 1900. ICES Journal of marine Science, 48: 253-280.

Rijnsdorp, A. D., 1992. Long-term effects of fishing in North Sea plaice. Universiteid van Amsterdam. 220 pp.

Rijnsdorp, A. D., 1994. Population-regulating processes during the adult phase in flatfish. Netherlands Journal of Sea Research, 32: 207-223.

Rochet, M. J., 1998. Short term effects of fishing on life history traits of fishes. ICES Journal of marine Science, 55: 371-391.

Rochet, M. J., Submitted. Does the concept of spawning per recruit make sense?

Schaffer, W. M., and Elson, P. F., 1975. The adaptive significance of variations in life history among local populations of atlantic salmon in North America. Ecology (New York), 56: 577-590.

Simpson, A. C., 1959. The spawning of the Plaice (Pleuronectes platessa) in the North Sea. Fishery Investigations, London, Series II, 22: $111 \mathrm{p}$.

Smith, P. E., 1985. Year-class strength and survival of 0-group clupeoids. Canadian Journal of Fisheries and Aquatic Sciences, 42: 69-82.

Smith, S. J., Hunt, J. J., and Rivard, D., eds. 1993. Risk evaluation and biological reference points for fisheries management. Canadian Special Publications of Fisheries and Aquatic Sciences, 120, Department of Fisheries and Oceans, Ottawa.

Solemdal, P., 1997. Maternal effects - a link between the past and the future. Journal of Sea Research, 37: 213-227.

Trippel, E. A., 1995. Age at maturity as a stress indicator in fisheries. Bioscience, 45: 759-771.

Trippel, E. A., 1998. Egg size and viability and seasonal offspring production of young Atlantic cod. Transactions of the American Fisheries Society, 127: 339-359. 
Trippel, E. A., Kjesbu, O. S., and Solemdal, P., 1997. Effects of adult age and size structure on reproductive output in marine fishes. In: R. C. Chambers and E. A. Trippel (Editors), Early life history and recruitment in fish populations. Chapman and Hall, London, pp 29-62.

Tuljapurkar, S., 1990. Population dynamics in variable environments. Lecture Notes in Biomathematics,

Tuljapurkar, S., 1997. Stochastic matrix models. In: S. Tuljapurkar and H. Caswell (Editors), Structured-population models in marine, terrestrial, and freshwater systems. Chapman and Hall, New York, pp 59-87.

Turnock, J., Wilkins, M., Saelens, M., and Lauth, R., 1994. Status of West Coast Dover Sole in 1994. Appendices to the status of the Pacific Coast ground fish fishery through 1994 and recommanded acceptable biological catches for 1995, Appendix C, 62 pp.

Vaughan, D. S., and Saila, S. B., 1976. A method for determining mortality rates using the Leslie matrix. Transactions of the American Fisheries Society, 105: 380-383.

Walters, C. J., and Ludwig, D., 1981. Effects of measurement errors on the assessment of stock-recruitment relationships. Canadian Journal of Fisheries and Aquatic Sciences, 38: 704-710.

Ware, D. M., 1985. Life history characteristics, reproductive value, and resilience of Pacific herring (Clupea harengus pallasi). Canadian Journal of Fisheries and Aquatic Sciences, 42: 127-137. 